\title{
Epstein-Barr Virus Nuclear Antigen (EBNA)-1 Carboxy-Terminal and EBNA-4 Sequence Polymorphisms in Nasal Natural Killer/T-Cell Lymphoma in the United States
}

\author{
Karl Gaal, Lawrence M. Weiss, Wen-Gang Chen, Yuan-Yuan Chen, and \\ Daniel A. Arber \\ Division of Pathology, City of Hope National Medical Center, Duarte, California
}

\begin{abstract}
SUMMARY: Epstein-Barr virus (EBV) polymorphisms were examined in 12 cases of nasal natural killer (NK)/T-cell lymphoma diagnosed in the United States (U.S.-NL) with respect to the EBV-associated nuclear antigen (EBNA)-1 carboxy (C)-terminal region and the EBNA-4 region. A single dominant EBV strain was found in all cases. EBNA-1 sequences were remarkably homogeneous, showing either a P-ala (2/12) or P-ala variant (9/12) sequence. Other EBNA-1 subtypes known to be common in U.S.-reactive samples, such as P-thr or V-leu, were not identified. The final case had a base deletion with frame shift and premature stop codon. EBNA-1 C-terminal amino acid substitutions were common at codons 499 (10/12 cases), 502 (7/12), 524 (9/12), and 528 (6/12), all previously reported "hot spots." However, unlike previous reports of other EBV-associated neoplastic and reactive tissues, mutations were absent at residues 487 and 492 . Mutations within HLA-A11-restricted immunogenic EBNA-4 epitopes 399-408 and 416-424 occurred in 3 of 12 cases but were not associated with HLA-A11 status. In summary, the exclusive finding of P-ala variant or P-ala EBNA-1 sequences in U.S.-NL cases differs from that reported in U.S.-reactive and non-U.S.-NL cases. Although the significance of this difference is not known for certain, it may be related to geographic and/or site-specific variations, rather than oncogenicity per se. (Lab Invest 2002, 82:957-962).
\end{abstract}

$E$ pstein-Barr virus (EBV) is found in essentially all cases of nasal natural killer/T-cell lymphoma (NL) and has been shown to be clonally integrated, implying a role in lymphomagenesis (Ho et al, 1990; Jaffe et al, 1996). The hypothesis that certain strains of EBV are associated with malignant transformation or with certain tumor types has been an area of active investigation. EBV gene polymorphisms have been demonstrated in a variety of EBV-associated tumors, including endemic Burkitt's lymphoma, Hodgkin's disease, immune deficiency-related lymphomas, gastric carcinoma, and nasopharyngeal carcinoma, as well as in EBV-positive reactive tissues and cultured lymphoblastoid cell lines (Bhatia et al, 1996; Chang et al, 1999; Chen et al, 1998; Fassone et al, 2000; Greiner et al, 2000; Gutierrez et al, 1997; Habeshaw et al, 1999; MacKenzie et al, 1999; Sandvej et al, 2000; Wrightham et al, 1995). Although some earlier studies suggested association of particular EBV strains with certain malignancies (Bhatia et al, 1996; Gutierrez et al, 1997), many subsequent studies have not confirmed this and, instead, have concluded that EBV sequence differ-

\section{DOI: 10.1097/01.LAB.0000020416.66825.A0}

Received April 9, 2002.

Address reprint requests to: Dr. Karl Gaal, Division of Pathology, City of Hope National Medical Center, 1500 East Duarte Road, Duarte, CA 91010.E-mail:kgaal@coh.org ences reflect geographic variations rather than any oncogenic potential (Chang et al, 1999; Chen et al, 1998; Fassone et al, 2000; Habeshaw et al, 1999; MacKenzie et al, 1999; Sandvej et al, 2000).

EBV gene polymorphism has been less well studied in NL, and only a few reports are present in the literature. Gutierrez et al (1998) studied EBNA-1 in 39 $\mathrm{NL}$ cases from Mexico and Peru and reported the presence of multiple EBNA-1 subtypes within most $(33 / 39)$ of their cases, suggesting ongoing in vivo mutation as the source of the heterogeneity. No particular EBNA-1 subtype emerged, although mutations at codon 487 were common. Only one other study has examined EBNA-1 in NL, reporting on only two Chinese NL cases amongst other EBV-associated tumors (Sandvej et al, 2000). Chiang et al (1999) has reported on EBV gene polymorphisms at other genetic loci (LMP1, EBNA-2, and EBNA-3C) in 23 Chinese NL cases. In contrast to Gutierrez et al (1998), Chiang et al (1999) detected only a single virus strain in nearly all cases. A predominance of the LMP1 30-bp deletion variant was seen in the tumor cases (91\%); however, this LMP1 deletion variant was also quite common $(63 \%)$ in the non-neoplastic nasal tissue of the Chinese population reported in the same study. The issue of EBV gene polymorphisms in NL, therefore, remains unsettled. Furthermore, no studies have examined NL cases from the U.S. or Western populations, where the tumors are much more rarely seen. 
EBNA-1 has received much attention in studies of EBV-associated tumors. The EBNA-1 gene is essential for the maintenance of the viral genome in latently infected cells and is consistently expressed in all EBV-associated tumors. Sequence analysis studies of EBNA-1 have focused on the C-terminal region, which contains a probable DNA binding-dimerization domain at residues 467-583 (Ambinder et al, 1991). Variations in EBNA-1 C-terminus have been classified according to the schema of Bhatia and colleagues relative to the prototype B95.8 virus, termed $\mathrm{P}$-ala because of the presence of alanine at codon 487 (Bhatia et al, 1996; Gutierrez et al, 1997). The other prototype (P-thr) has a similar sequence but with threonine at 487 . Variants (V-val, V-pro, and V-leu) are also named for substitutions at 487 but have more substantial additional amino acid differences.

EBNA-4 is another latently expressed gene and is the major HLA-A11-restricted target (at epitopes 399408 and 416-424) for the cytotoxic T lymphocyte (CTL) response to EBV infection in HLA-A11-positive hosts (Gavioli et al, 1993). Escape from CTL surveillance has been postulated as a mechanism for EBV persistence, and, theoretically, could play a role in EBV-associated neoplastic transformation. High mutation rates within these immunodominant epitopes in a highly HLA-A11-positive population from Papua New Guinea were attributed by de Campos-Lima et al $(1993,1994)$ to immune selection pressure and were thought to contribute to persistence of these EBNA-4 variant strains. Subsequent studies, however, support the notion that variations in EBNA-4 sequence are primarily related to geographic variations and are unrelated to HLA-A11 status, being just as common in populations with a low HLA-A11 frequency (Burrows et al, 1996; Khanna et al, 1997). EBNA-4 mutations have also been identified commonly in EBVassociated Hodgkin's disease, gastric carcinoma, and AIDS-related lymphomas from the U.S., Brazil, and Japan and were unrelated to HLA-A11 status (Chu et al, 1999). No data have been published on EBNA-4 in NL to our knowledge.

In this study, we examined EBV sequence variation in 12 U.S. cases of NL with respect to the EBNA-1 C-terminal region and EBNA-4 HLA-A11-restricted target epitopes. HLA-A11 status was determined as well. The goal was to compare EBV sequences with the limited reported data on other non-U.S.-NL and with known EBV subtype distribution in nonneoplastic tissues from the U.S. population.

\section{Results}

\section{EBNA-1 C-Terminus}

Results of EBNA-1 C-terminal sequencing are detailed in Table 1. Based on the classification schema of Bhatia and colleagues (1996), which is primarily dependent on the sequence at codon 487, the EBNA-1 strains from the U.S.-NL cases are classified as $\mathrm{P}$-ala (two cases) or as variants of P-ala (nine cases). Requisite to their designation as $\mathrm{P}$-ala or $\mathrm{P}$-ala variants, all
U.S.-NL cases lacked any mutation at 487. One case had a base deletion at 487 , with a frame-shift and predicted premature stop codon at 494 .

The nine cases with mutations averaged 4.4 base substitutions relative to $\mathrm{B} 95.8$ ( $\mathrm{P}$-ala). Mutations were limited to six codons, only one of which (codon 520) was always silent. Mutations resulting in amino acid substitutions were common at codons 499 (8/12 cases), 502 (7/12), 524 (8/12), and 528 (6/12). Codon 500 had an amino acid substitution in 2 of 12 cases. Amino acid substitutions were remarkably consistent, invariably resulting in the following substitutions relative to B95.8: Asp $\rightarrow$ Glu (codon 499), Glu $\rightarrow$ Asp (500), $\mathrm{Thr} \rightarrow$ Asn (502), Thr $\rightarrow$ Ile (524), and Ile $\rightarrow$ Val (528). Five cases had an identical EBNA-1 sequence with base substitutions at codons 499, 502, 520, 524, and 528. Two additional cases were very similar, sharing mutations at 499, 502, 520, and 524; but they lacked a mutation at 528 and had an additional mutation at 500 . Of the remaining two cases, one had a single amino acid substitution at 524, and the other had two substitutions at 499 and 528.

\section{EBNA-4 and HLA-A11}

EBNA-4 mutations and HLA-A11 status of U.S.-NL cases are detailed in Table 2. EBNA-4 mutations within epitopes 399-408 and 416-424 were identified in $25 \%$ (3/12) of U.S.-NL cases. Two of these cases had three mutations each, two of which were identical (399 Ala $\rightarrow$ Ser, 400 Val $\rightarrow$ Leu). The other mutation was at codon 424 (Lys $\rightarrow$ Asn) in one case, whereas in the other case the mutation was outside the area of interest. A third case had mutations at 400 (Val $\rightarrow$ Met) and 417 ( $\mathrm{Val} \rightarrow$ Leu). A fourth case had two mutations, both outside the epitopes of interest. Four sites (399, 400, 417, and 424) accounted for all the EBNA-4 mutations within the HLA-A11-restricted immunogenic epitopes of interest. Four (33\%) of 12 cases were HLA-A11 positive. EBNA-4 mutations within epitopes 399-408 or 416-424 were present in 1 (25\%) of 4 HLA-A11-positive cases and 2 (25\%) of 8 HLA-A11-negative cases. One additional HLA-A11positive case had two EBNA-4 mutations, both of which were outside the epitopes of interest.

\section{Discussion}

NL are essentially always EBV associated and usually demonstrate infection in most of the tumor cells by in situ hybridization for EBV-encoded RNA. NL occur uncommonly in the U.S. but share identical morphologic, immunohistochemical, and molecular features with their more frequent counterparts in Asia and certain South and Central American populations (Arber et al, 1993; Gaal et al, 2000; Jaffe et al, 1996). Characterization of EBV polymorphisms to assess for tumorigenic strains or association with specific tumor types has been more extensively studied in other EBV-associated malignancies. Most studies have attributed EBV strain variation to geographic differences, although there are some reports suggesting 
Table 1. EBNA-1 Carboxy-Terminal Mutations in U.S.-NL

\begin{tabular}{|c|c|c|c|c|c|c|c|c|c|c|c|}
\hline & 487 & 492 & 499 & 500 & 502 & 520 & 524 & 525 & 528 & 533 & Subtype \\
\hline \multirow[t]{2}{*}{ B95.8 } & GCT & AGT & GAC & GAA & ACT & CTA & ACT & GCC & ATT & СТT & P-ala \\
\hline & Ala & Ser & Asp & Glu & Thr & Leu & Thr & Ala & Ile & Leu & \\
\hline \multirow{2}{*}{ P-thr } & АCT & TGT & $G A T$ & & & CTC & ATT & & & & P-thr \\
\hline & Thr & Cys & $A s p$ & & & Leu & Ile & & & & \\
\hline \multirow[t]{2}{*}{ V-leu } & CTT & TGT & GAG & GAT & AAT & CTC & ATT & GGC & & & V-leu \\
\hline & Leu & Cys & Glu & Asp & Asn & Leu & Ile & Gly & & & \\
\hline \multirow[t]{2}{*}{ V-val } & GTT & & GAG & & AAT & CTC & ATT & & & ATT & V-val \\
\hline & Val & & Glu & & Asn & Leu & Ile & & & Ile & \\
\hline NL-1 & & & & & & & & & & & P-ala \\
\hline NL-2 & & & & & & & & & & & P-ala \\
\hline \multirow[t]{2}{*}{ NL-3 } & & & GAG & & AAT & CTC & ATT & & GTT & & $\mathrm{P}$-ala variant \\
\hline & & & Glu & & Asn & Leu & Ile & & Val & & \\
\hline \multirow[t]{2}{*}{ NL-4 } & & & GAG & & AAT & CTC & ATT & & GTT & & P-ala variant \\
\hline & & & Glu & & Asn & Leu & Ile & & Val & & \\
\hline \multirow[t]{2}{*}{ NL-5 } & & & GAG & & AAT & CTC & ATT & & GTT & & $\mathrm{P}$-ala variant \\
\hline & & & Glu & & Asn & Leu & Ile & & Val & & \\
\hline \multirow[t]{2}{*}{ NL-6 } & & & GAG & & AAT & CTC & ATT & & GTT & & P-ala variant \\
\hline & & & Glu & & Asn & Leu & Ile & & Val & & \\
\hline \multirow[t]{2}{*}{ NL-7 } & & & GAG & & AAT & CTC & ATT & & GTT & & P-ala variant \\
\hline & & & Glu & & & 1 & Ile & & Val & & \\
\hline \multirow[t]{2}{*}{ NL-8 } & & & GAG & GAC & AAT & СТC & ATT & & & & P-ala variant \\
\hline & & & Glu & Asp & Asn & Leu & $\mathrm{He}$ & & & & \\
\hline \multirow[t]{2}{*}{ NL-9 } & & & GAG & GAT & AAT & CTC & ATT & & & & P-ala variant \\
\hline & & & Glu & Asp & Asn & Leu & Ile & & & & \\
\hline \multirow[t]{2}{*}{ NL-10 } & & & $G A T$ & & & CTC & ATT & & & & P-ala variant \\
\hline & & & $A s p$ & & & & Ile & & & & \\
\hline NL-11 & & & GAA & & & & & & GTT & & P-ala variant \\
\hline & & & Glu & & & & & & Val & & \\
\hline $\mathrm{NL}-12^{a}$ & Loss G & & & & & & & & & & \\
\hline
\end{tabular}

U.S.-NL, nasal natural killer/T-cell lymphoma diagnosed in the U.S.

Base substitutions relative to B95.8 are in bold type. Blanks indicate identity with B95.8. Sequences of P-thr, V-leu, and V-val are referenced in the text and are provided for comparison. Silent mutations are in italics.

${ }^{a} \mathrm{NL}-12$ had a single base deletion at 487 resulting in predicted premature stop codon at residue 494.

Table 2. EBNA-4 Mutations and HLA-A11 Status of U.S.-NL

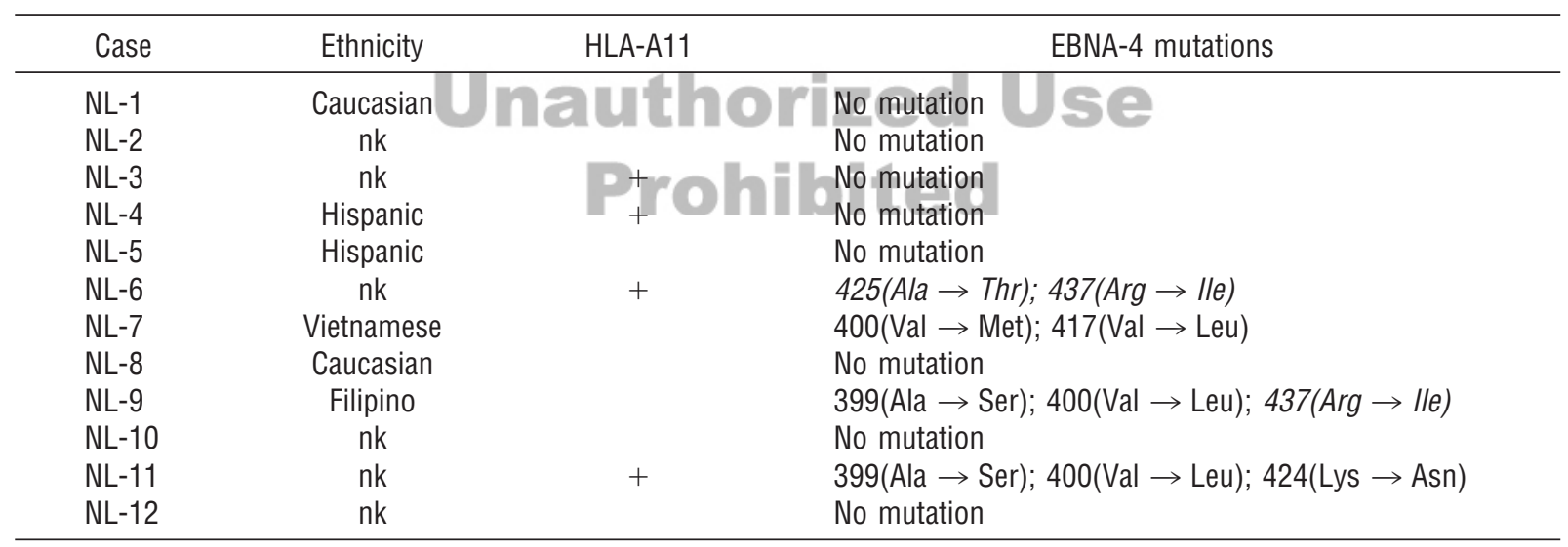

nk, not known.

Amino acid substitutions are with respect to B95.8 sequence. Mutations outside EBNA-4 HLA-A11-restricted immunogenic epitopes (399-408 and 416-424) are in italics.

tumorigenic varieties. Comparison with geographic controls is necessary to critically evaluate results.

EBNA-1 C-terminal mutations (relative to B95.8) were commonly found in U.S.-NL (83\% of cases) and showed surprising homogeneity, being classified either as P-ala
(2/12) or P-ala variants (9/12). Five U.S.-NL cases had an identical EBNA-1 pattern, with base substitutions at 499, $502,520,524$, and 528 . On review of the literature, this pattern is identical in codons studied to only a single case (1/29 studied) of posttransplant-related lymphopro- 
liferative disorder termed P-ala ${ }^{\mathrm{VI}}$ (Greiner et al, 2000) and a single case (1/11 studied) of primary effusion lymphoma termed P-ala" (Fassone et al, 2000). One of the Peruvian/Mexican-NL cases (NL4) of Gutierrez and coworkers was also similar, sharing the same five base substitutions but also had an additional mutation at codon 529 (Gutierrez et al, 1998). Complete sequence data were not published, however, for all the NL cases of Gutierrez et al, and others may have been similar. Some commonly noted sites of EBV EBNA-1 strain variation in other studies, such as codons 487,492 , and 525 , did not show any mutations in U.S.-NL cases. The relative homogeneity of the U.S.-NL cases seems even more striking considering the variable ethnic distribution of the U.S. cases (two Caucasian, two Hispanic, one Vietnamese, one Filipino, six not known).

EBNA-1 variants in U.S.-NL differ from prevailing EBNA-1 strains in U.S. non-neoplastic tissues based on available data (Table 3). Our group previously studied 11 cases of EBV-positive reactive lymphoid tissue in the U.S. population and found $45 \% \mathrm{P}$-thr and variants, 36\% V-leu and variants, and $18 \% \mathrm{P}$-ala and variants (Chen et al, 1998). Greiner et al (2000) sequenced 25 nonneoplastic U.S. EBV-positive samples from blood ( $n$ 9), lung or bronchial fluid ( $n=7$ ), colorectal biopsy specimens $(n=2)$, and lymph node $(n=1)$ and found a similar distribution, showing 68\% P-thr and variants, $24 \%$ V-leu and variants, and 8\% P-ala. Prototypes P-ala and $\mathrm{P}$-thr were also the most commonly detected variants in reactive peripheral blood lymphocytes of American donors by Bhatia et al (1996) (precise sequences not provided), although they were often found with other EBV subtypes. V-leu was not detected in any of those peripheral blood lymphocyte samples. Based on these studies, the predominant EBNA-1 subtypes in the U.S. population from different sources (blood/and tissue) seem to be a mixture of P-thr, V-leu, and P-ala. The consistent presence of $\mathrm{P}$-ala and $\mathrm{P}$-ala variants in U.S.$\mathrm{NL}$, and the absence of P-thr or V-leu subtypes, therefore, differs from known EBNA-1 strain distribution in the U.S. population and suggests an association. However, because of the lack of data on nasal site-specific EBNA-1 strains in the U.S., we cannot completely exclude the possibility that the bias toward $\mathrm{P}$-ala variants is related to nasal site rather than a lymphomagenic strain per se. We were not able to detect EBV in several randomly chosen benign nasal biopsy specimens by PCR.

Bhatia's classification of EBNA-1 is primarily based on the amino acid present at codon 487, which originally seemed to be more or less predictive of the remainder of the C-terminal sequence. However, as more data on EBNA-1 has emerged, heterogeneity of strains with the same 487 residue is greater than originally expected, expanding the number of variants. Classification according to the original schema, therefore, seems less informative. For example, the most common variant detected in this study is classified as a P-ala variant because of lack of mutation at 487; however, it actually differs by fewer base substitutions from V-val (only three substitutions, with Val at 487) than from $\mathrm{P}$-ala (five substitutions).

A slightly different approach in analyzing EBNA-1 variations is to focus on particular mutational "hot spots," rather than attempting to classify as prototype or variants. Amino acid substitutions relative to $\mathbf{B 9 5 . 8}$ at EBNA-1 C-terminal codons 499, 502, and 524 were common regardless of whether neoplastic or reactive, and regardless of locale of NL (U.S., Mexico/Peru, or China) (Table 3). Substitutions at 499, 502, and 524 are therefore likely normal polymorphisms without oncogenic potential. In contrast, the U.S.-NL cases differed strikingly from reactive tissues in lacking mutations at 487, 492, and 525. Although the lack of mutations at these codons seems associated with U.S.-NL cases, these same sites have been previously reported as frequently mutated in the large series of Mexican/Peruvian NL cases of Gutierrez et al (1998) and the two Chinese-NL cases of Sandvej et al (2000) (Table 3). Polymorphisms at 487, 492, or 525, therefore, are also unlikely to harbor oncogenic potential. The reason for the variance of EBNA-1 sequences in

Table 3. Comparison of EBNA-1 Mutations in Nasal Lymphomas and U.S.-Reactive Tissues

\begin{tabular}{|c|c|c|c|c|c|c|c|c|c|c|}
\hline & $\begin{array}{c}487 \\
(A L A)\end{array}$ & $\begin{array}{c}492 \\
\text { (SER) }\end{array}$ & $\begin{array}{l}499 \\
\text { (ASP) }\end{array}$ & $\begin{array}{l}500 \\
\text { (GLU) }\end{array}$ & $\begin{array}{c}502 \\
\text { (THR) }\end{array}$ & $\begin{array}{l}520 \\
\text { (LEU) }\end{array}$ & $\begin{array}{c}524 \\
\text { (THR) }\end{array}$ & $\begin{array}{l}525 \\
\text { (ALA) }\end{array}$ & $\begin{array}{l}528 \\
(\text { ILE) }\end{array}$ & $\begin{array}{l}533 \\
\text { (LEU) }\end{array}$ \\
\hline $\begin{array}{l}\text { U.S.-Reactive } \\
\text { (Chen) }\end{array}$ & $\begin{array}{c}9 / 11 \\
\text { (5 THR, } 4 \text { LEU) }\end{array}$ & $\begin{array}{r}9 / 11 \\
\text { (CYS) }\end{array}$ & $\begin{array}{r}6 / 11 \\
(G L U)\end{array}$ & $\begin{array}{r}4 / 11 \\
\text { (ASP) }\end{array}$ & $\begin{array}{r}4 / 11 \\
\text { (ASN) }\end{array}$ & $0 / 11$ & $\begin{array}{c}11 / 11 \\
(10 \mathrm{ILE}, 1 \mathrm{VAL})\end{array}$ & $\begin{array}{r}4 / 11 \\
(G L Y)\end{array}$ & $0 / 11$ & $0 / 11$ \\
\hline $\begin{array}{l}\text { U.S.-Reactive } \\
\text { (Greiner) }\end{array}$ & $\begin{array}{c}23 / 25 \\
\text { (17 THR, } 6 \text { LEU) }\end{array}$ & $\begin{array}{l}23 / 25 \\
\text { (CYS) }\end{array}$ & $\begin{array}{r}6 / 25 \\
(G L U)\end{array}$ & $\begin{array}{r}6 / 25 \\
\text { (ASP) }\end{array}$ & $\begin{array}{r}6 / 25 \\
\text { (ASN) }\end{array}$ & $0 / 25$ & $\begin{array}{l}23 / 25 \\
(\mathrm{ILE})\end{array}$ & $\begin{array}{r}7 / 25 \\
(G L Y)\end{array}$ & $0 / 25$ & ND \\
\hline U.S.-NL & $0 / 12$ & $0 / 12$ & $\begin{array}{r}8 / 12 \\
\text { (GLU) }\end{array}$ & $\begin{array}{r}2 / 12 \\
\text { (ASP) }\end{array}$ & $\begin{array}{r}7 / 12 \\
\text { (ASN) }\end{array}$ & $0 / 12$ & $\begin{array}{l}9 / 12 \\
\text { (ILE) }\end{array}$ & $0 / 12$ & $\begin{array}{r}6 / 12 \\
\text { (VAL) }\end{array}$ & $0 / 12$ \\
\hline $\begin{array}{l}\text { MEX/PERU- } \\
\text { NL } \\
\text { (Gutierrez) }^{a}\end{array}$ & $\begin{array}{c}30 / 39 \\
\text { (VARIABLE) }\end{array}$ & $\begin{array}{l}27 / 39 \\
\text { (CYS) }\end{array}$ & $\begin{array}{l}37 / 39 \\
\text { (GLU) }\end{array}$ & $\begin{array}{l}24 / 39 \\
\text { (ASP) }\end{array}$ & $\begin{array}{l}37 / 39 \\
\text { (ASN) }\end{array}$ & $0 / 39$ & $\begin{array}{l}38 / 39 \\
\text { (ILE) }\end{array}$ & $\begin{array}{l}22 / 39 \\
\text { (GLY) }\end{array}$ & $\begin{array}{l}22 / 39 \\
\text { (VAL) }\end{array}$ & ND \\
\hline $\begin{array}{l}\text { CHINESE-NL } \\
\text { (Sandvej) }\end{array}$ & $\begin{array}{c}2 / 2 \\
\text { (VAL) }\end{array}$ & $0 / 2$ & $\begin{array}{r}2 / 2 \\
(\mathrm{GLU})\end{array}$ & $0 / 2$ & $\begin{array}{r}2 / 2 \\
\text { (ASN) }\end{array}$ & $0 / 2$ & $\begin{array}{l}2 / 2 \\
\text { (ILE) }\end{array}$ & $0 / 2$ & $0 / 2$ & $\begin{array}{l}2 / 2 \\
\text { (ILE) }\end{array}$ \\
\hline
\end{tabular}

ND, not done.

Numbers of cases with amino acid substitutions are listed with respect to B95.8 C-terminal sequence (top row). With the exception of codon 487 , the amino acid substitutions are remarkably consistent. U.S.-NL cases differ from U.S.-reactive and non-U.S.-NL primarily at 487, 492 , and 525.

${ }^{a}$ Mutations are estimated from a bar graph in the report of Gutierrez et al. (1998), and the amino acid substitutions are those listed as most commonly observed (precise sequence data not reported). Data from all other studies is taken from precise published sequences. 
U.S.-NL cases with non-U.S.-NL cases in the literature may not only be geographic, as has been found in other EBV-associated malignancies, but may also be related to site. Unfortunately, there is not sufficient data to assess either of these possibilities. Normal geographic EBNA-1 strain variation in Central and South America is not known; nor is there data on nasal site-specific EBNA-1 strains in non-neoplastic tissues. Detailed EBNA-1 analysis from areas with higher NL frequency, such as in Asia, would also be very interesting but has not yet been reported.

A single dominant EBNA-1 C-terminal sequence was identified in each U.S.-NL. Chiang et al (1999) also detected only a single dominant EBV population in 23 Chinese NL cases based on LMP1 analysis, whereas mixed strains were more commonly seen $(29 \%)$ in nonneoplastic nasal tissue. In contrast, the majority (33/39) of Mexican/Peruvian-NL cases by Gutierrez et al (1998) showed a multiplicity of EBNA-1 substrains using subcloning technique. Although subcloning was not performed, our results favor the presence of a single clonal EBV population in NL and do not support the postulated phenomenon of ongoing mutation.

No relation between HLA-A11 status and EBNA-4 mutations was detected in U.S.-NL cases. Mutations within epitopes 399-408 and 416-424, which have been shown to be the major immunogenic epitopes of the HLA-A11-restricted CTL response to EBV infection, were equally as common (25\%) in HLA-A11-negative and HLA-A11-positive cases. Most (70\%) of the EBNA-4 mutations detected in this study were at residues 399 , 400,417 , and 424 , all of which were previously identified hot spots showing similar amino acid mutations in other EBV-associated tumors (Burrows et al, 1996; Chu et al, 1999; de Campos-Lima et al, 1994).

In summary, we report data on EBV polymorphisms at EBNA-4 and EBNA-1 C-terminus in 12 U.S.-NL cases. EBNA-4 mutations are not related to HLAA11 status in U.S.-NL. All U.S.-NL cases showed a single dominant EBNA-1 strain, with a striking relative uniformity of mutation pattern. The exclusive finding of $\mathrm{P}$-ala and variants in our study differs from the prevalent EBNA-1 strains reported from nonneoplastic U.S. samples (geographic control), as well as from NL cases from other countries. Despite this difference, statements about the oncogenicity of any particular EBV strain would be premature, in part because data on EBNA-1 strains in normal U.S. nasal tissue (site-specific control) are lacking. Furthermore, although there was a uniformity of EBNA-1 subtypes in this study, the variation of EBNA-1 subtypes in the NL cases reported in the literature argues against the association of any particular strain with lymphomagenesis.

\section{Materials and Methods}

\section{Cases}

Twelve cases of NL lymphoma diagnosed in the U.S. were studied. The features of these cases have been previously reported with regard to clinical presenta- tion, histology, immunophenotype, in situ hybridization for EBV-encoded RNA (EBER-ISH), and T-cell receptor gamma chain gene rearrangement (Gaal et al, 2000). All cases were positive for EBV EBER-ISH.

\section{PCR Amplification for EBNA-1 C-Terminus and EBNA-4}

Genomic DNA was extracted from 5 - $\mu \mathrm{m}$ cut sections of formalin-fixed, paraffin-embedded tissue blocks, using $0.2 \mathrm{mg} / \mathrm{ml}$ proteinase $\mathrm{K}$ digestion overnight, followed by denaturation by boiling. PCR studies were performed in a $30-\mu \mathrm{l}$ mixture containing $50 \mathrm{mmol} / \mathrm{L}$ $\mathrm{KCl}, 10 \mathrm{mmol} / \mathrm{L}$ Tris buffer (pH 8.3), $50 \mu \mathrm{mol} / \mathrm{L}$ of each deoxynucleotide triphosphate, $2.5 \mathrm{mmol} / \mathrm{L} \mathrm{MgCl} 2,1 \mathrm{U}$ of Taq polymerase (Perkin Elmer, Foster City, California), and $20 \mathrm{pmol}$ of each primer. For the EBNA-1 C-terminus, the primers were C1 (5'-GAA ATT TGA GAA CAT TGC AGA AGG-3') and C2 (5'-GGG TCC AGG GGC CAT TCC AAA-3'). For the EBNA4 gene, two sets of oligonucleotide primers were used, flanking the EBNA-4 region of prototype B95.8 EBV virus encoding epitopes 399-408 and 416-424: EBNA-4 ${ }^{+}$ primer ' 5'-GAGGAGGAAGACAAGAGTGG-3' and EBNA-4- primer 5'-GATTCAGGCGTGGCTCTTGG-3; nested EBNA-4 ${ }^{+}$primer 5'-TACCGCAAACACTGCCGTAC- $3^{\prime}$ and nested EBNA-4 ${ }^{-}$primer $5^{\prime}$-CTGTTCTGGCTGCCTTCTTC-3'. After an initial denaturation for 3 minutes at $95^{\circ} \mathrm{C}, 45$ amplification cycles were performed as follows: denaturing at $94^{\circ} \mathrm{C}$ for 30 seconds, annealing at $58^{\circ} \mathrm{C}$ for 30 seconds, and extension at $72^{\circ} \mathrm{C}$ for 40 seconds. A final extension at $72^{\circ} \mathrm{C}$ for 3 minutes completed the PCR amplification. Separate laboratories were used for PCR set up and post-PCR / work to minimize the possibility of contamination.

\section{Bidirectional PCR Amplification of Specific Alleles for the HLA-11 LocuS}

Genomic DNA was extracted as above. Amplification of an HLA-11 unique sequence (524-560 of HLA-A exon 3) was performed by first amplifying region 456-617 using HLA-A11 primer $^{+}$5'-GGACCTGCGCTCTTGGAC-3' and HLA-A11 primer $^{-}$5'-GTGCGCTGCAGCGTCTCC-3'. The HLA-A11-specific sequence was determined by the bidirectional PCR amplification of specific alleles method, as previously described (Bottema and Sommer, 1993; Liu et al, 1997; Sommer et al, 1999).

\section{DNA Sequencing}

Thirty microliters of PCR products were run on a $2 \%$ agarose gel, and the product band(s) cut out, purified using a Qiaex gel extraction kit (Qiagen, Hilden, Germany), and resuspended in $30 \mu$ l of water. The products were sequenced with the BigDye Terminator DNA sequencing kit (Applied Biosystems, Foster City, California), using the manufacturer's recommended conditions, and analyzed with the ABI PRISM 310 Genetic Analyzer (Applied Biosystems). 


\section{References}

Ambinder RF, Mullen MA, Judde J-G, Spangler G, Venkatesh $J$, and Magrath IT (1991). Functional domains of Epstein-Barr virus nuclear antigen EBNA-1. J Virol 65:1466-1478.

Arber DA, Weiss LM, Albujar PF, Chen Y-Y, and Jaffe ES (1993). Nasal lymphomas in Peru: high incidence of T-cell immunophenotype and Epstein-Barr virus infection. Am J Surg Pathol 17:392-399.

Bhatia K, Raj A, Gutierrez MI, Judde J-G, Spangler G, Venkatesh H, and Magrath IT (1996). Variation in the sequence of Epstein Barr virus nuclear antigen 1 in normal peripheral blood lymphocytes and in Burkitt's lymphomas. Oncogene 13:177-181.

Bottema CDK and Sommer SS (1993). PCR amplification of specific alleles: Rapid detection of known mutations and polymorphisms. Mutation Res 288:93-102.

Burrows JM, Burrows SR, Poulsen LM, Sculley TB, Moss DJ, and Khanna R (1996). Unusually high frequency of EpsteinBarr virus genetic variants in Papua New Guinea that can escape cytotoxic T-cell recognition: Implication for virus evolution. J Virol 70(4):2490-2496.

Chang KL, Chen Y-Y, Chen W-G, Hayashi K, Bacchi C, Bacchi $M$, and Weiss LM (1999). EBNA-1 sequences in Brazilian and American patients with Hodgkin's disease. Blood 94(1):244-250.

Chen Y-Y, Chang KL, Chen W-G, Shibata D, Hayashi K, and Weiss LM (1998). Epstein-Barr virus-associated nuclear antigen-1 carboxy-terminal gene sequences in Japanese and American patients with gastric carcinoma. Lab Invest 78 : 877-882.

Chiang AKS, Wong KY, Liang ACT, and Srivastava G (1999). Comparative analysis of Epstein-Barr virus gene polymorphisms in nasal T/NK-cell lymphomas and normal nasal tissues: Implications on virus strain selection in malignancy. Int J Cancer 80:356-364.

Chu PG, Chang KL, Chen W-G, Chen Y-Y, Shibata D, Hayashi K, Bacchi C, Bacchi M, and Weiss LM (1999). Epstein-Barr virus (EBV) nuclear antigen (EBNA)-4 mutation in EBV-associated malignancies in three different populations. Am J Pathol 155:941-947.

de Campos-Lima PO, Gavioli R, Zhang Q-J, Wallace LE, Dolcetti R, Rowe M, Rickinson AB, and Masucci MG (1993). HLA-A11 epitope loss isolates of Epstein-Barr virus from a highly $A 11+$ population. Science 260:98-100.

de Campos-Lima PO, Levitsky V, Brooks J, Lee SP, Hu LF, Rickinson AB, and Masucci MG (1994). T cell responses and virus evolution: Loss of HLA A11-restricted CTL epitopes in Epstein-Barr virus isolates from highly A11-positive populations by selective mutation of anchor residues. J Exp Med 179:1297-1305.

Fassone L, Bhatia K, Gutierrez M, Capello D, Gloghini A, Dolcetti R, Vivenza D, Ascoli V, Lo Coco F, Pagani L, Dotti G, Rambaldi A, Raphael M, Tirelli U, Saglio G, Magrath IT, Carbone A, and Gaidano G (2000). Molecular profile of Epstein-Barr virus infection in HHV-8-positive primary effusion lymphoma. Leukemia 14:271-277.

Gaal K, Sun NCJ, Hernandez AM, and Arber DA (2000). Sinonasal NK/T-cell lymphomas in the United States. Am J Surg Pathol 24:1511-1517.
Gavioli R, Kurilla MG, de Campos-Lima PO, Wallace LE, Dolcetti R, Murray RJ, Rickinson $A B$, and Masucci MG (1993). Multiple HLA A11-restricted cytotoxic T-lymphocyte epitopes of different immunogenicities in the Epstein-Barr virus-encoded nuclear antigen 4. J Virol 67:1572-1578.

Greiner TC, Abou-Elella AA, Smir BN, Orazi A, Hinrichs S, Anderson J, Gross T, Bierman P, and Hauke R (2000). Molecular epidemiology of EBNA-1 substrains of Epstein-Barr virus in posttransplant lymphoproliferative disorders which have infrequent p53 mutations. Leuk Lymphoma 38:563-576.

Gutierrez MI, Raj A, Spangler G, Sharma A, Hussain A, Judde J-G, Tsao SW, Yuen PW, Joab I, Magrath IT, and Bhatia K (1997). Sequence variations in EBNA-1 may dictate restriction of tissue distribution of Epstein-Barr virus in normal and tumour cells. J Gen Virol 78:1663-1670.

Gutierrez MI, Spangler G, Kingma D, Raffeld M, Guerrero I, Misad O, Jaffe ES, Magrath IT, and Bhatia K (1998). EpsteinBarr virus in nasal lymphomas contains multiple ongoing mutations in the EBNA-1 gene. Blood 92:600-606.

Habeshaw G, Yao QY, Bell Al, Morton D, and Rickinson AB (1999). Epstein-Barr virus nuclear antigen 1 sequences in endemic and sporadic Burkitt's lymphoma reflect virus strains prevalent in different geographic areas. J Virol 73:965-975.

Ho FC, Srivastava G, Loke SL, Fu KH, Leung BP, Liang R, and Choy D (1990). Presence of Epstein-Barr virus DNA in nasal lymphomas of B and T cell type. Hematol Oncol 8:271-281.

Jaffe ES, Chan JKC, Su I-J, Frizzera G, Mori S, Feller AC, and Ho FCS (1996). Report of the workshop on nasal and related extranodal angiocentric T/natural killer cell lymphomas. Am J Surg Pathol 20:103-111.

Khanna R, Slade RW, Poulsen L, Moss DJ, Burrows SR, Nicholls J, and Burrows JM (1997). Evolutionary dynamics of genetic variation in Epstein-Barr virus isolates of diverse geographical origins: Evidence for immune pressureindependent genetic drift. J Virol 71(11):8340-8346.

Liu Q, Thorland EC, Heit JA, and Sommer SS (1997). Overlapping PCR for bidirectional amplification of specific alleles: A rapid one tube method for simultaneously differentiating homozygotes and heterozygotes. Genome Res 7:389-398.

MacKenzie J, Gray D, Pinto-Paes R, Barrezueta LFM, Armstrong AA, Alexander FA, McGeoch DJ, and Jarrett RF (1999). Analysis of Epstein-Barr virus (EBV) nuclear antigen 1 subtypes in EBV-associated lymphomas from Brazil and the United Kingdom. J Gen Virol 80:2741-2745.

Sandvej K, Zhou X-G, and Hamilton-Dutoit S (2000). EBNA-1 sequence variation in Danish and Chinese EBV-associated tumors: Evidence for geographical polymorphism but not for tumour-specific subtype restriction. J Pathol (191):127-131.

Sommer SS, Cassady JD, Sobell HL, and Bottema CDK (1999). A novel method for detecting point mutations or polymorphisms and its application to population screening for carriers of phenylketonuria. Mayo Clin Proc 64:1362-1372.

Wrightham MN, Stewart JP, Janjua NJ, Pepper S, Sample C, Rooney CM, and Arrand JR (1995). Antigenic and sequence variation in the $\mathrm{C}$-terminal unique domain of the Epstein-Barr virus nuclear antigen EBNA-1. Virology 208:521-530. 